\title{
A Twelve-Beam Steering Low Profile Patch Antenna with Shorting Vias for Vehicular Applications
}

\author{
Arpan Pal, Member, IEEE, Amit Mehta, Senior Member, IEEE, Dariush Mirshekar-Syahkal, Fellow, \\ IEEE, Hisamatsu Nakano, Life Fellow, IEEE
}

\begin{abstract}
A low-profile twelve-beam printed patch antenna is presented for pattern reconfigurable applications. The patch is fed at the four sides using coaxial feeds. Diagonal lines of vias are inserted on the patch surface to restrict currents to the edges. Whilst majority of patch antennas have an axial beam pattern, the proposed antenna produces twelve different tilted beams. When one of its four feeds on the sides is excited and the remaining feeds are open circuited, the antenna generates a linearly polarized tilted beam $\left(6.2 \mathrm{dBi}, \theta_{\max }=30^{\circ}\right)$. This beam is directed away from feeding patch corner. Therefore, the antenna can steer its tilted beam in four different space quadrants in front of the antenna by exciting one feed at a time. The antenna is also capable of generating eight other beams using multiple feed excitations. They are four additional titled beams $\left(6.03 \mathrm{dBi}, \theta_{\max }=30^{\circ}\right)$, two tilted-twin beam $\left(6.5 \mathrm{dBi}, \theta_{\max }= \pm 36^{\circ}\right)$, one semi-doughnut beam $(5.8 \mathrm{dBi})$ and one axial beam $(8.2 \mathrm{dBi})$. The antenna is designed to operate at test frequency of $2.4 \mathrm{GHz}$ and has a height $=1.5 \mathrm{~mm}$ ( $\left.\lambda_{0} / 83\right)$. The impedance matching to $50 \Omega$ is achieved using right angle slots etched on the patch antenna.
\end{abstract}

Index Terms-Microstrip patch antenna, SIW antenna, low-profile antenna, pattern reconfigurable antenna, beam steering, tilted beam.

\section{INTRODUCTION}

$\mathrm{B}$ eam steering antennas are gaining tremendous attention for a variety of different applications, such as cellular and satellite communication, radar system, and Wireless Local Area Network (WLAN) [1]-[3]. These antennas can provide an efficient way to mitigate the multi-path fading phenomena since they can form the beam toward the intended direction, enabling the network to avoid the interference and noise sources. Consequently, they offer higher Single to Noise Ratio (SNR), higher diversity gain and higher rate data-transmission. With smart cities and sensor technology developing to improve our lives we now need, more than ever before, steerable antennas for enabling sensors to achieve longer ranges, higher throughputs and lower power consumption (longer battery up times).

Typically, large wireless networks can use phased array antennas [4] for beam steering and pattern reconfiguration. However, phased array antennas are heavy and expensive, require multiple antenna elements, phase shifters (with inevitable losses) and complex signal processing for their operation. Therefore, they are not suitable for low price modern commercial portable wireless transceivers.

As an alternative, single element Beam Steering Antennas (BSAs) [5]-[21] have been proposed recently for manoeuvring antenna radiation beam in space. Being single element, these antennas are small, lightweight, require small signal processing and either need no or diminutive phase shifters. The rectangular spiral antenna [5]-[8] was the initial one in this class. To steer its beam, the current distribution over the spiral arm is varied using switches, but the antenna has limited beam steering capability and suffers from pattern variations. Four space quadrant consistent patterns switching were achieved using star [9] and printed square loop antennas [10]-[13]. These employed four feeds which are switched one at a time. The same concept was exploited by [14]-[16]. Another antenna, quasi feed switching antenna, employing $\mathrm{p}-\mathrm{i}-\mathrm{n}$ diodes to switch the pattern in four different space quadrants is reported in [17]. In [18] circular patch surrounded by four parasitic patches that act either as reflector or director depending on the p-i-n diode switching arrangement steers its beam up to nine different angular directions. In [19], a 4-port antenna is proposed for providing four distinct beams. In [20], four microstrip patches are excited by 4-ports to provide two beams which are either linearly polarized conical beam or circularly polarized axial beam. In [21], a 2-port circular microstrip patch antenna is proposed, capable of producing steerable dipole-like radiation patterns for scanning entire azimuth plane. This, however, failed to cover the axial directions. All these approaches provided only tilted beams and no other possible radiation patterns. This meant a large space above the antenna was left uncovered within the $3 \mathrm{~dB}$ of the main lobe. To fill the gap, this new work focuses on multiport antennas to cover nearly all spatial zones using multi beam radiation.

In this work, we have exploited a specially grounded square patch antenna with four ports for generating 12 different beams to cover most of the space above the antenna. They are 8 tilted, two tilted-twin, one semi-doughnut and one axial. The first 11 beams are either single or multiport feed but do not require any phase shifters. Only the last axial beam requires three fixed phase shifters.

The proposed antenna is of a low-profile design $(1.5 \mathrm{~mm}$ at $2.4 \mathrm{GHz} \sim \lambda_{0} / 83$ ) which is capable of effective beam steering in 
both $\mathrm{E}$ and $\mathrm{H}$ planes. Similar to [9]-[16], it keeps patterns, polarization and VSWR the same for all switched beams. We have exploited edge radiations from the microstrip square patch antenna to produce tilted beams, which can be steered in space using RF switches. To encourage edge radiation, the square patch has rows of shorting vias, similar to partial SIW [22]-[29], which forces current to stay on the edges. Further, we have undertaken slot matching for edge feeding the patch, similar to [30], which helps the antenna to have low profile. The antenna performances are simulated using CST Microwave studio based on Finite Integration Technique in Time Domain (FIT-TD) [31]. Table I provides a comparison of this work with those of similar works [14]-[16] and [25]-[26]. It shows that this work is new from the aspect of low profile structure, highest tilt, and multiple reconfigurable radiation beams.

Table. I. Performance comparison between the proposed antenna and antennas reported in [14], [15], [16], [25] and [26].

\begin{tabular}{|c|c|c|c|c|c|c|}
\hline & $\begin{array}{c}\text { This } \\
\text { work }\end{array}$ & {$[14]$} & {$[15]$} & {$[16]$} & {$[25]$} & {$[26]$} \\
\hline $\begin{array}{c}\text { Operating } \\
\text { frequency } \\
\text { GHz }\end{array}$ & 2.4 & 2.4 & 2.9 & 3.5 & 10.8 & 5.2 \\
\hline $\begin{array}{c}\text { No. of } \\
\text { achievable } \\
\text { beams }\end{array}$ & 12 & 4 & 5 & 4 & 1 & 1 \\
\hline Height & $\lambda_{0} / 83$ & $\lambda_{0} / 19$ & $\lambda_{0} / 12$ & $\lambda_{0} / 29$ & $\lambda_{0} / 18$ & $\lambda_{0} / 37$ \\
\hline Size & $0.8 \lambda_{0}$ & $0.8 \lambda_{0}$ \\
$\times 0.8 \lambda_{0}$ & $\times 0.8 \lambda_{0}$ & $\begin{array}{c}0.7 \lambda_{0} \\
\times 0.7 \lambda_{0}\end{array}$ & $\begin{array}{c}0.8 \lambda_{0} \\
\times 0.8 \lambda_{0}\end{array}$ & $\begin{array}{c}1.43 \lambda_{0} \\
\times 1.25 \lambda_{0}\end{array}$ & $\begin{array}{c}0.7 \lambda_{0} \\
\times 0.7 \lambda_{0}\end{array}$ \\
\hline $\begin{array}{c}\text { Tilt angle } \\
\text { (degree) }\end{array}$ & $30-43$ & 36 & 28 & 31 & 35 & 0 \\
\hline $\begin{array}{c}\text { Gain (dBi) } \\
\text { Polarization }\end{array}$ & $5.7-8.2$ & 5.34 & 7.2 & 8.27 & 7.13 & 7.04 \\
\hline $\begin{array}{c}\text { Beam } \\
\text { steering }\end{array}$ & Yes & Yes & YP & LP & CP & CP \\
\hline $\begin{array}{c}\text { Patterns } \\
\text { consistent } \\
\text { in four } \\
\text { quadrants }\end{array}$ & Yes & Yes & Yes & Yes & No & No \\
\hline
\end{tabular}

\section{ANTENNA CONFIGURATION AND REFLECTION COEFFICIENT}

Fig. 1 shows the top and side views of the proposed antenna. The square patch is etched on a Taconic [32] TLP-5 substrate $\left(\varepsilon_{\mathrm{r}}=2.2, \tan \delta=0.009\right)$ having an area $100 \mathrm{~mm} \times 100 \mathrm{~mm}$ and a thickness of $h=1.5 \mathrm{~mm}$. The whole antenna structure is backed by a ground plane. Each side of the square patch has a length $l_{3}=76 \mathrm{~mm}$. From the bottom, the patch is fed at four sides using the coaxial line. The feeding points are A, B, C and D and each of them is located at a distance $l_{l}=32.2 \mathrm{~mm}$ from one corner and $l_{2}=43.8 \mathrm{~mm}$ from the other corner. Four right-angle shaped slots with dimensions $l_{4}=5 \mathrm{~mm}, l_{5}=4.9 \mathrm{~mm}, l_{6}=2.4 \mathrm{~mm}, l_{7}=2.1 \mathrm{~mm}$, $l_{8}=1.2 \mathrm{~mm}, l_{9}=1.6 \mathrm{~mm}, l_{10}=1 \mathrm{~mm} \mathrm{~g}_{1}=2.3 \mathrm{~mm}$ and $\mathrm{g}_{2}=2 \mathrm{~mm}$ are cut (formed) in the vicinity of feeding points for achieving $50 \Omega$ impedance match, Fig. 1.

Also, as seen in Fig. 1, the four rows of periodic conducting vias shorting the patch to the ground are placed diagonally between the two successive feeding points making an angle $\alpha=45^{\circ}$ to the edge of a side. The first via is placed at a distance $d_{l}=5.2 \mathrm{~mm}$ away from the edge of the horizontal slot. Each set of periodic vias consist of 23 conducting (copper) rods having a diameter of $r=0.6 \mathrm{~mm}$ and the distance between the two consecutive vias is $d=2 \mathrm{~mm}$.

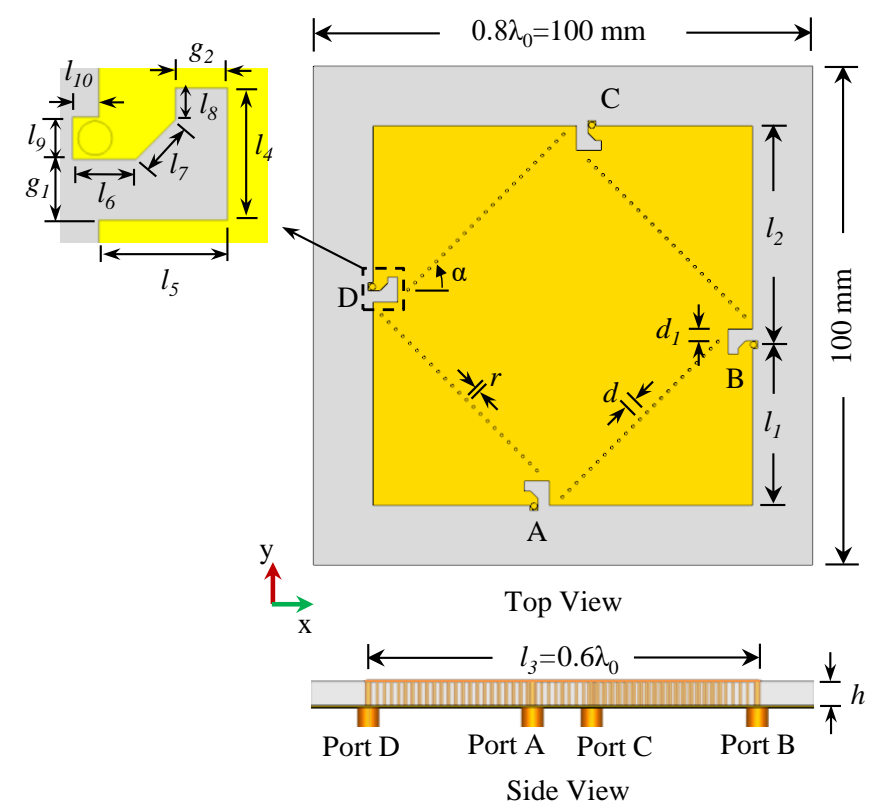

Fig. 1. Top and side views of the proposed antenna.

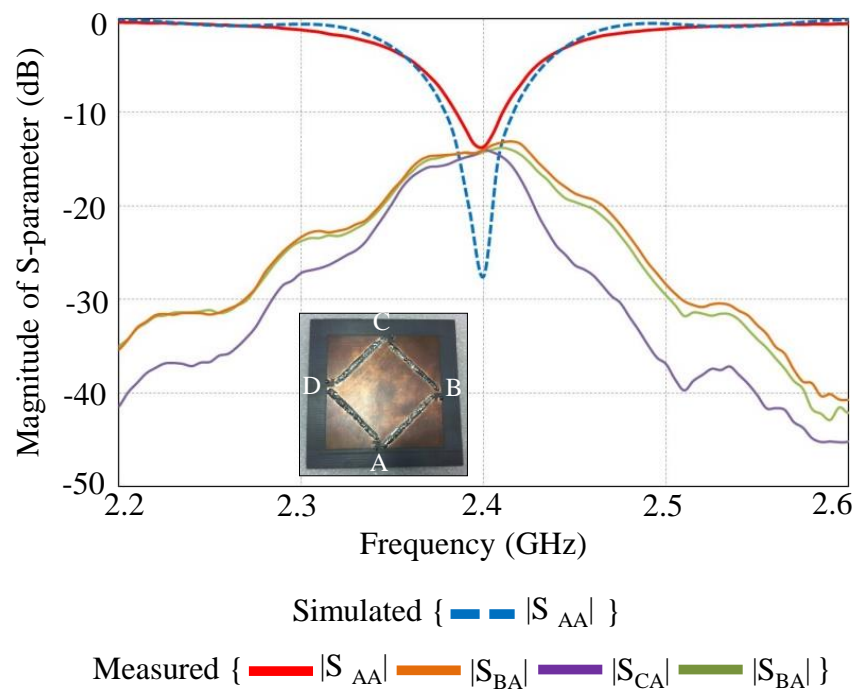

Fig. 2. Simulated and measured reflection coefficients of the antenna for port A excitation and measured isolation at other ports. (Inset) prototype antenna.

Fig. 2 shows the reflection coefficient $\left(\left|\mathrm{S}_{\mathrm{AA}}\right|\right)$ of the antenna when only port $\mathrm{A}$ is excited and remaining ports $(\mathrm{B}, \mathrm{C}$ and $\mathrm{D})$ are open circuited. The antenna operates in $2.4 \mathrm{GHz}$ $(802.11 \mathrm{~b} / \mathrm{g} / \mathrm{n})$ license free band and covers the frequency range from $2.38 \mathrm{GHz}$ to $2.42 \mathrm{GHz}$. Since the other ports are symmetrical with respect to the antenna structure the reflection coefficient of those ports are expected to be similar to that of port $\mathrm{A}$. The measured isolation (e.g. $\left.\left|\mathrm{S}_{\mathrm{BA}}\right|\right)$ between port $\mathrm{A}$ and the remaining ports are more than $15 \mathrm{~dB}$. 


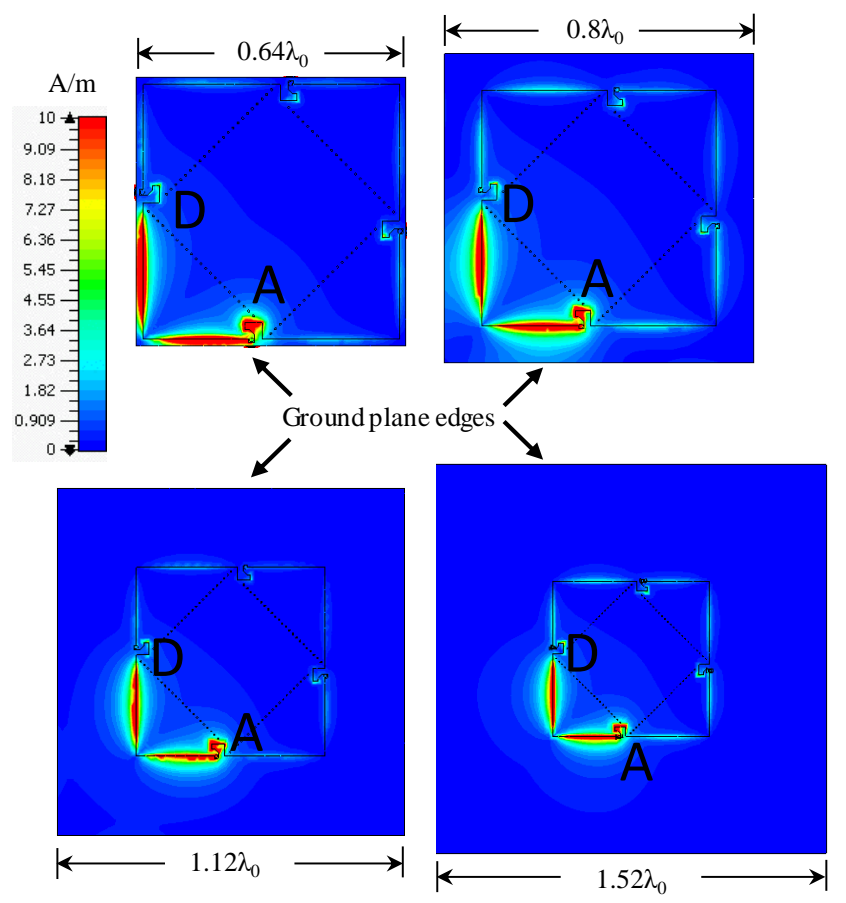

Fig. 3. Simulated current distributions for port A excitation for different sizes of ground plane of the antenna. (Patch dimensions constant at $0.64 \lambda_{0} \times 0.64 \lambda_{0}$ for all four cases).

\section{RADIATION PATTERN RESULTS}

Fig. 3 shows the current distributions of the antenna for different sizes $\left(0.64 \lambda_{0} \times 0.64 \lambda_{0}, 0.8 \lambda_{0} \times 0.8 \lambda_{0}\right.$ etc $)$ of the grounded-substrate (Fig. 1) used in the antenna when port A is excited and the remaining ports are open circuited. It provides a qualitative display of how a tilted beam is formed. Considering Fig. 3, the formation of the tilted beam can be attributed to the interaction of the ground edges with the field from the aperture of the antenna. The periodic vias in the antenna, Fig. 1, behave as a short-circuited electric wall and consequently block the current flow to the other parts of the patch. Therefore, the currents due to port A excitation are concentrated just around the A-D edges of the patch. These A-D edge currents produces antenna aperture fields which interact with the ground plane side edges. This interaction produces a tilted far field beam directed away from A-D corner of the patch. It was further found that it was the size of the ground that influenced the beam tilt angle, as shown in Fig.4.

Fig. 4 shows the variation of the beam tilt of the maximum radiation in both elevation $\left(\theta_{\max }\right)$ and azimuth $\left(\phi_{\max }\right.$ at cut angle of $\phi=45^{\circ}$ ) planes for different dimensions of the ground plane. It is found that when the side length of the square ground plane is increased from $0.6 \lambda_{0}$ to $0.8 \lambda_{0}$, the tilt angle increases from $16^{\circ}$ to $30^{\circ}$. The tilt angle decreases with a larger dimension than $0.8 \lambda_{0}$ and the radiation pattern becomes axial (axial beam) beyond the dimension of $1.2 \lambda_{0}$. The direction of the maximum radiation in the azimuth plane remains constant at $45^{\circ}$. Since, the ground plane dimension of $0.8 \lambda_{0} \times 0.8 \lambda_{0}(100 \mathrm{~mm} \times 100 \mathrm{~mm})$ exhibits the maximum tilt, $\theta_{\max }=30^{\circ}$, it is selected for designing the proposed antenna.

Fig. 5 shows polar cuts of the normalized radiation pattern of the antenna at the operating frequency of $2.4 \mathrm{GHz}$ when only port $\mathrm{A}$ is excited and remaining ports (B, C and D) are open circuited. The antenna generates a tilted beam with the maximum radiated field located at $\theta_{\max }=30^{\circ}$ away from the zenith (z-axis) and directed away $\left(\phi_{\max }=45^{\circ}\right)$ from the adjacent corner. The antenna has a maximum gain of $6.2 \mathrm{dBi}$ in the direction of maximum radiated field. The main lobe is linearly polarized $\left(E_{\theta}\right)$ and the cross-polarized components $\left(E_{\phi}\right)$ are approximately $25 \mathrm{~dB}$ down in the direction of the main beam.

Since ports A, B, C and D are symmetrically located around the patch, the associated radiation patterns of any of these ports are similar. Therefore, by exciting A, B, C or D individually (one at a time), the antenna can steer its linearly polarized tilted radiation $\left(\theta_{\max }=30^{\circ}\right)$ in four quadrants of $\left(\phi_{\max }=45^{\circ}, \phi_{\max }=135^{\circ}\right.$ $\phi_{\max }=225^{\circ}$ and $\phi_{\max }=315^{\circ}$ ).

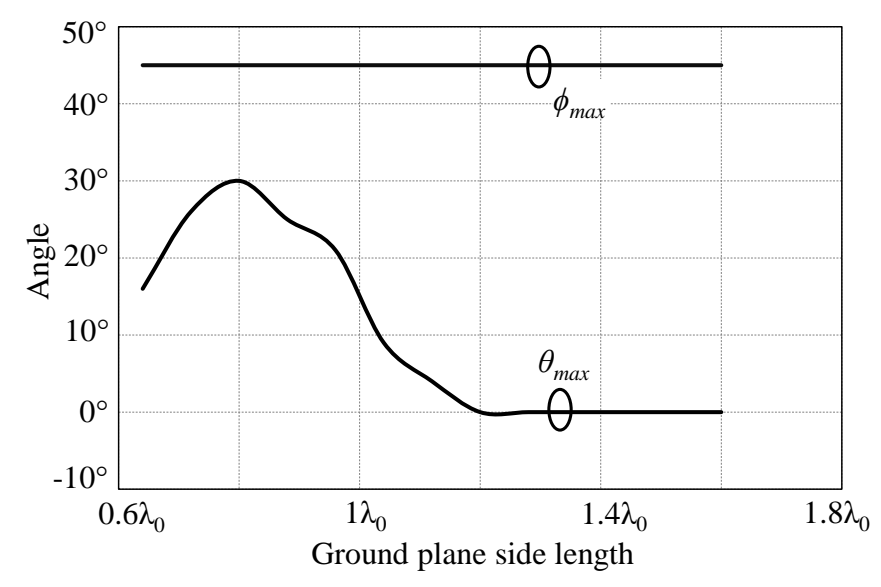

Fig. 4. Variation of the radiation pattern tilt angle with the variation of ground plane dimension. (Patch dimensions constant at $0.64 \lambda_{0} \times 0.64$ ).

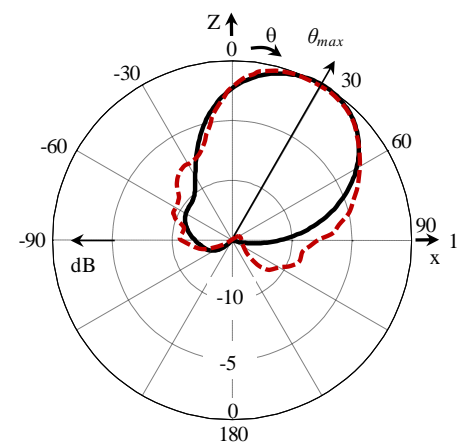

(a) Elevation plane

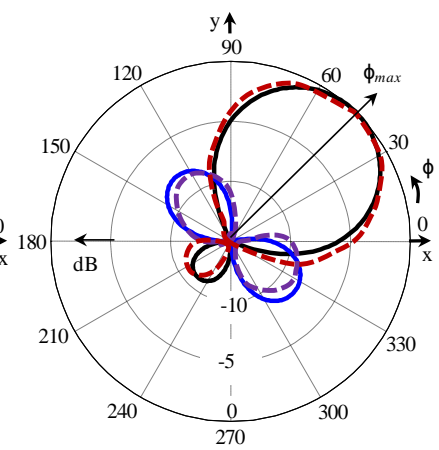

(b) Azimuth plane

$$
\begin{aligned}
& \mathrm{E}_{\theta}\{- \text { Simulated, }-\boldsymbol{-} \text { Measured }\} \\
& \mathrm{E}_{\phi}\{- \text { Simulated, }-\boldsymbol{-} \text { Measured }\}
\end{aligned}
$$

Fig. 5. Tilted beam at $2.4 \mathrm{GHz}$ with only Port A excited (a) Elevation cut at $\phi_{\max }=45^{\circ}$, (b) Azimuth cut at $\theta_{\max }=30^{\circ}$.

\section{MULTI-PORT FEEDING FOR ADDITIONAL BEAMS}

As discussed in the previous section, the proposed antenna can generate four tilted beams by switching through its feed. However, in the middle of two beams $\left(\phi_{\max }=0^{\circ}, 90^{\circ}, 180^{\circ}\right.$ and $270^{\circ}$ ) the gain of the antenna drops by $5 \mathrm{~dB}$ (Fig. 4(b)). This creates signal power drops (holes) in the full azimuth beam steering. In addition, the maximum gain in the zenith direction is only $4 \mathrm{dBi}$. This is a drawback if axial transmit / reception services are required. These limitations of the antenna can be 
overcome by exciting multiple ports simultaneously. In fact, in this way, the proposed antenna can provide eight additional new beams. They are four titled beams directing towards the power-dropped azimuth directions, two tilted-twin beams, a semi-doughnut beam and an $8.2 \mathrm{dBi}$ high gain axial beam.

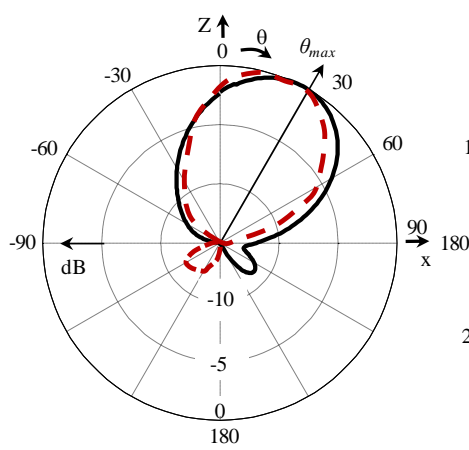

(a) Elevation plane

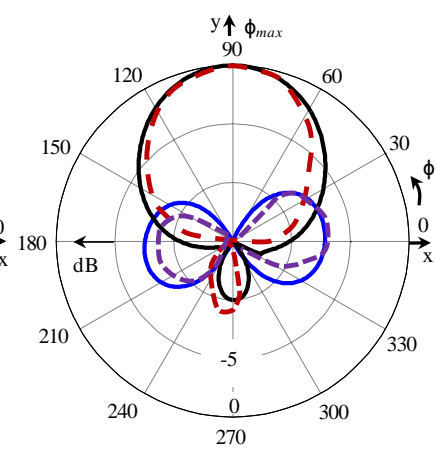

(b) Azimuth plane

$$
\begin{aligned}
& \mathrm{E}_{\theta}\{- \text { Simulated, }-\boldsymbol{-} \text { Measured }\} \\
& \mathrm{E}_{\phi}\{- \text { Simulated, }-\boldsymbol{E} \text { Measured }\}
\end{aligned}
$$

Fig. 6. Tilted beam at $2.4 \mathrm{GHz}$ with ports $\mathrm{A}$ and $\mathrm{B}$ excited simultaneously, (a) Elevation cut at $\phi_{\max }=90^{\circ}$, (b) Azimuth cut at $\theta_{\max }=30^{\circ}$.

\section{A. Additional four new tilted beams to enable seamless azimuth beam steering using dual feeding}

To recover the signal in power dropped zones two adjacent ports of the antenna are fed simultaneously with equal amplitudes and phases. This dual feeding generates a tilted beam directing towards a quadrant opposite to that of the left feeding port (observing from the top). For instance, if port A and port $\mathrm{B}$ are fed simultaneously, the antenna radiates a tilted beam of $\theta_{\max }=30^{\circ}$ in the direction of $\phi_{\max }=90^{\circ}$ (opposite to that of feeding port A). Fig. 6 shows the polar cuts of this new linearly polarized $\left(E_{\theta}\right)$ tilted beam with a gain of $6.03 \mathrm{dBi}$. Similarly by dual feeding port B and C, C and D, and D and A, a $6.03 \mathrm{~dB}$ titled beams can be generated in three quadrants $\phi_{\max }=180^{\circ}, \phi_{\max }=270^{\circ}$ and $\phi_{\max }=0^{\circ}$, respectively. Therefore, a complete seamless (signal power drop holes of less than $0.5 \mathrm{~dB}$ ) full-azimuth steering can be realized by combining both single and dual feeding configuration. This is shown in Fig 7.

\section{B. Tilted-twin beams using dual feeding}

Tilted-twin beams provide a theoretical doubling of network capacity without substantially increasing cost and size. At the same time, it can improve throughput and provide better, faster and consistent Quality of Services (QoS) to the subscribers [33]. We find that if two opposite ports are fed together with the same amplitude and phase, twin beam is generated. This twin beam has a gain of $6.5 \mathrm{dBi}$, same as that of single fed tilted beam. The direction of the twin beam is at the left diagonal to the line joining the two feeds (observing from the top). For instance, if ports $\mathrm{A}$ and $\mathrm{C}$ are excited together, the antenna provides a tilted-twin beam with $\theta_{\max }= \pm 36^{\circ}$ in the direction of $\phi_{\max }=45^{\circ}$ and $225^{\circ}$ (noted as $45^{\circ} / 225^{\circ}$ ). Fig. 8 shows the $3 \mathrm{D}$ pattern and polar cuts of tilted twin-beams due to ports $\mathrm{A}$ and $\mathrm{C}$ and each beam has a gain of $6.5 \mathrm{dBi}$ in the direction of maximum radiation. Similarly, another tilted-twin beam can be generated in the direction of $\phi_{\max }=135^{\circ} / 315^{\circ}$ by exciting ports $\mathrm{B}$ and D simultaneously with equal amplitude and phase.

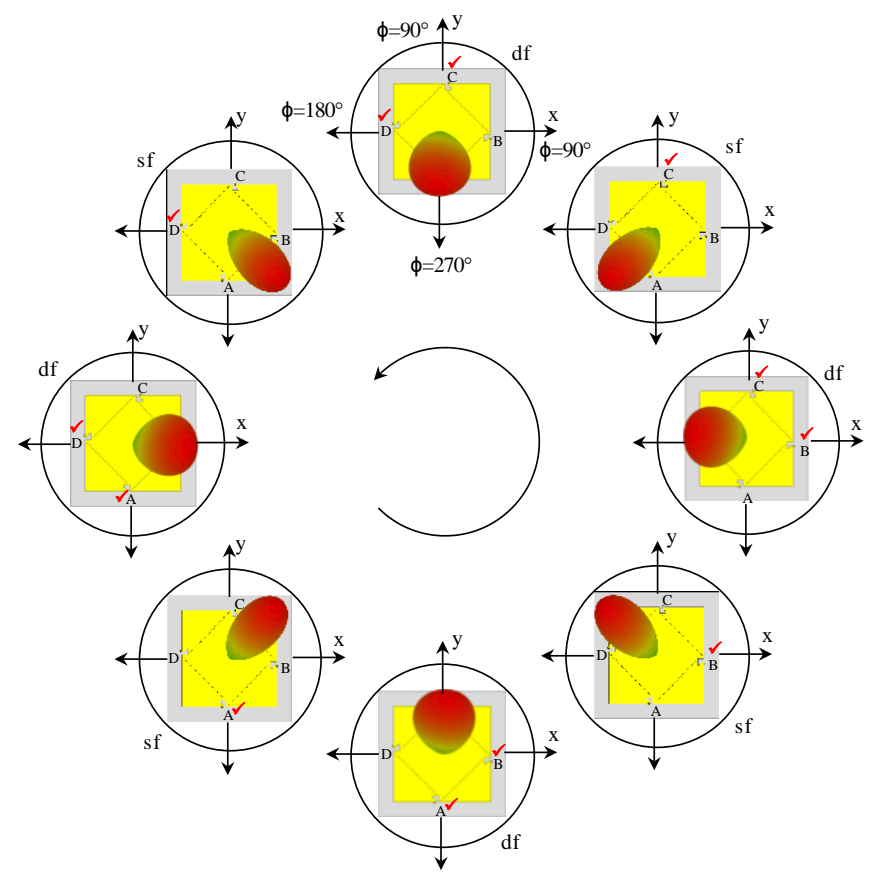

Fig. 7. Demonstration of beam steering with tilted beams using sf ('single feed' configuration) and df ('dual feed' configuration).

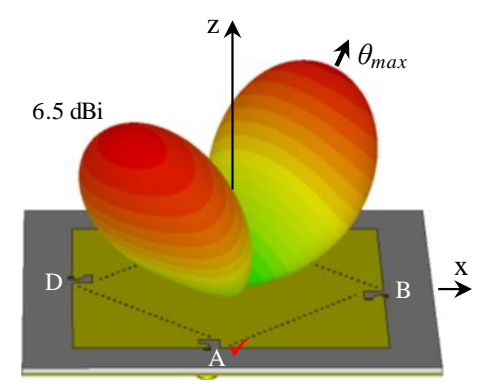

(a). $3 \mathrm{~d}$ pattern

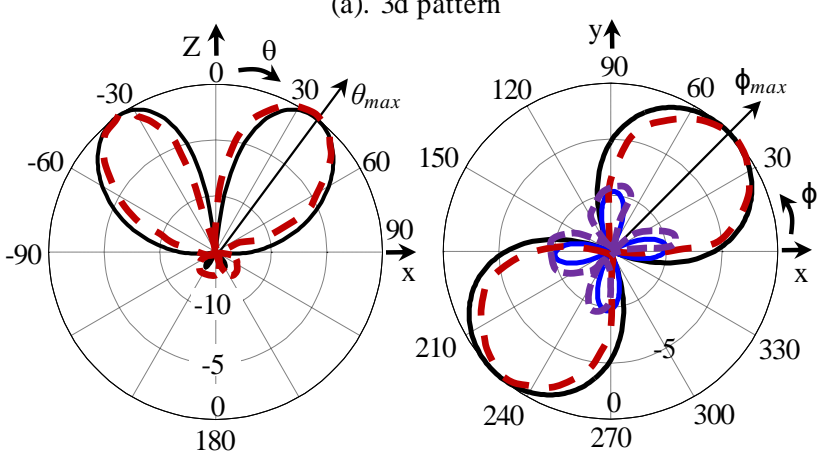

(b). Elevation plane at $\phi_{\max }=45^{\circ}$

(c). Azimuth plane at $\theta_{\max }=36^{\circ}$

$$
\begin{aligned}
& \mathrm{E}_{\theta}\{- \text { Simulated, }- \text { Measured }\} \\
& \mathrm{E}_{\phi}\{\rightleftharpoons \text { Simulated, }=- \text { Measured }\}
\end{aligned}
$$

Fig. 8. Tilted-twin beams at $2.4 \mathrm{GHz}$ with port $\mathrm{A}$ and $\mathrm{C}$ excited together; (a) 3D pattern, (b) Elevation cut at $\phi_{\max }=45^{\circ}$ and (c) Azimuth cut at $\theta_{\max }=36^{\circ}$. 


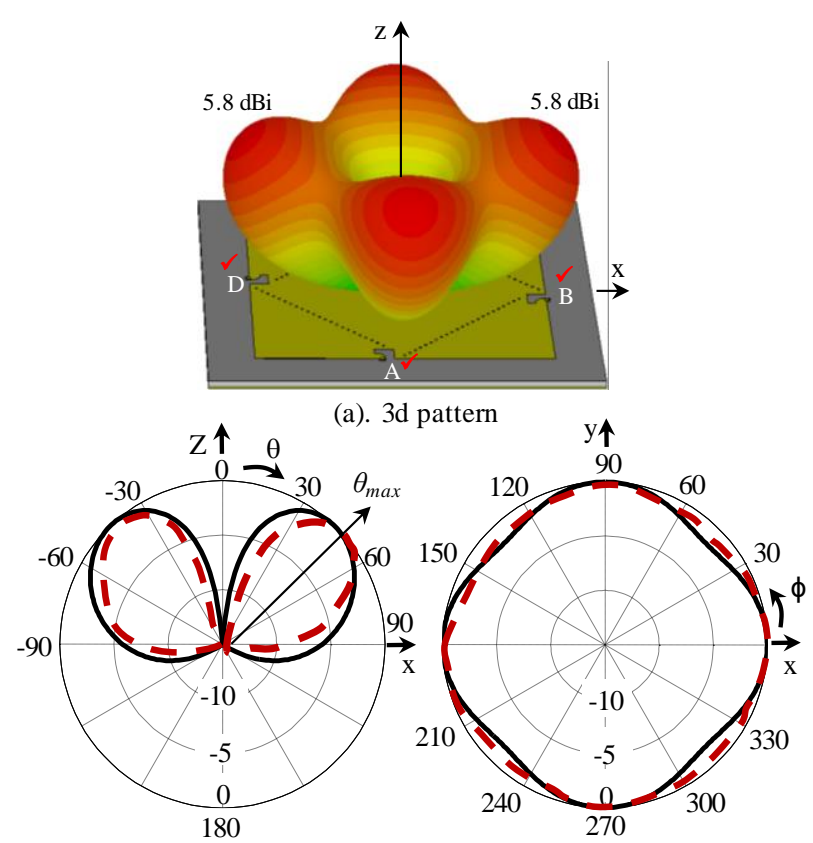

(b). Elevation plane at $\phi_{\max }=0^{\circ}$

(c). Azimuth plane at $\theta_{\max }=43^{\circ}$

$$
\begin{aligned}
& \mathrm{E}_{\theta}\{- \text { Simulated, } \boldsymbol{T} \text { Measured }\} \\
& \mathrm{E}_{\phi}\{\square \text { Simulated, } \square \text { Measured }\}
\end{aligned}
$$

Fig. 9. Semi-doughnut beam at $2.4 \mathrm{GHz}$; (a) 3D pattern, (b) At $\phi_{\max }=0^{\circ}$, and (c) at $\theta_{\max }=43^{\circ}$.

\section{Semi-doughnut beam using four port feeding}

Ideally, the antennas for vehicular communication systems have a radiation pattern which receives signals from all the side directions and nothing from top. This condition requires a semi-doughnut pattern [34]. It is found that besides having steerable tilted beams and tilted-twin beam, the antenna would provide semi-doughnut pattern. This is achieved by simultaneously exciting all the four ports with currents of equal amplitude and phase. Fig. 9 shows the 3D pattern and polar cuts of the semi-doughnut pattern. The antenna achieves the highest gain of $5.8 \mathrm{dBi}$ in the directions $\theta_{\max }=43^{\circ}$ and $\phi=0^{\circ}$, $90^{\circ}, 180^{\circ}$ and $270^{\circ}$. The magnitude of side lobes is well below $(<-20 \mathrm{~dB})$ that of the main lobe. The azimuth cut at $\theta_{\max }=43^{\circ}$ represents an excellent omnidirectional coverage and uniform gain over all azimuth angles $(\phi)$.

\section{Axial beams using four port feeding with phase shifters}

The off-boresight tilted beams and semi-doughnut beam are not suitable for the systems where signals may arrive directly from the top, such as from overhead low earth orbit satellite, balloon or an UAV. It is found that the proposed antenna can provide both linear and circular polarized axial beams. A linear polarized axial beam can be formed by exciting all four ports A, $\mathrm{B}, \mathrm{C}$ and D simultaneously with currents of equal amplitude and phase values of $0^{\circ}, 0^{\circ}, 180^{\circ}$ and $180^{\circ}$, respectively. Fig. 10 shows 3D pattern and polar cuts ( $x z$ - and $y z$-plane) of the axial beam. The main beam has a gain of $8.2 \mathrm{dBi}$ and cross polarized components are $40 \mathrm{~dB}$ down from that of the main beam. A circular polarized axial beam of gain $8.2 \mathrm{dBi}$ can also be generated if the phases for the four ports are in phase quadrature $\left(0^{\circ}, 90^{\circ}, 180^{\circ}\right.$ and $\left.270^{\circ}\right)[35]$.

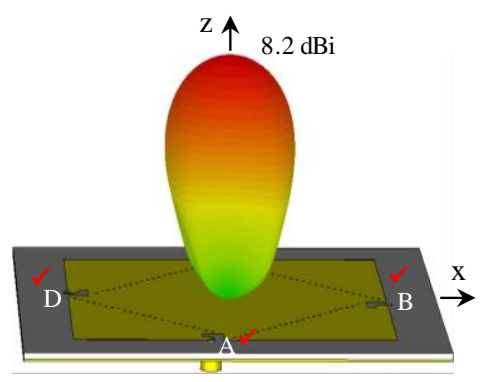

(a). 3d pattern

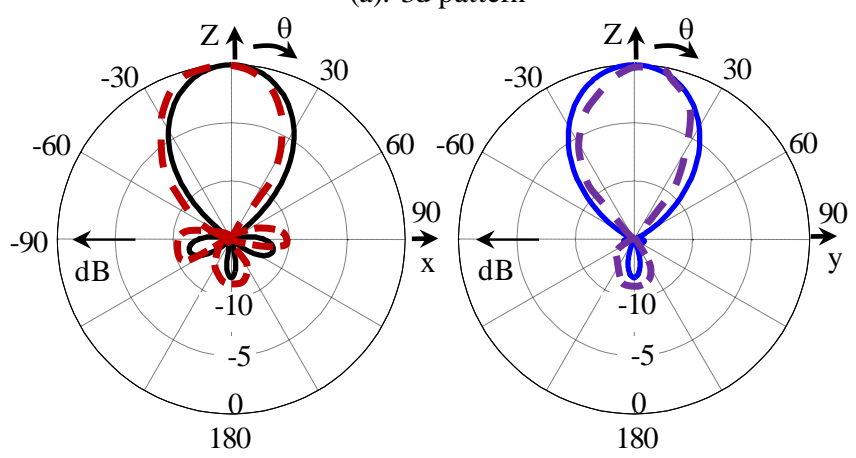

(b). at $\phi=0^{\circ}$

(c). at $\phi=90^{\circ}$

$$
\begin{aligned}
& \mathrm{E}_{\theta}\{- \text { Simulated, }- \text { Measured }\} \\
& \mathrm{E}_{\phi}\{- \text { Simulated, }=\text { Measured }\}
\end{aligned}
$$

Fig. 10. Axial beam at $2.4 \mathrm{GHz}$; (a) 3D pattern, (b) At $\phi_{\max }=0^{\circ}$, and (c) at $\phi_{\max }=90^{\circ}$.

\section{FREQUENCY RESPONSE OF GAIN AND EFFICIENCY}

Fig. 11 shows the variation of the total antenna efficiency for all five types of radiation beams: four single feeding tilted, four dual feeding tilted, two tilted-twins, one semi-doughnut and one axial beam. It is found that in a range of 2.384 to $2.412 \mathrm{GHz}$ the antenna exhibits a total efficiency of greater than $70 \%$ for all radiation beams, which is defined as 'Net efficient pattern bandwidth' $=28 \mathrm{MHz}(1.16 \%$ bandwidth $)$. This means that the proposed antenna is suitable for narrow band communications, especially for the narrow band Internet of Things (IoT) at lower frequency spectrum. For a higher frequency operating band, a scaled antenna for satellite communications at $30 \mathrm{GHz}(\mathrm{Ka}$ band) would offer a net $350 \mathrm{MHz}$ bandwidth. This is more than sufficient for even $4 \mathrm{k}$ high throughput internet access. At the test frequency of $2.4 \mathrm{GHz}$, single feeding tilted, dual feeding tilted, tilted-twin, semi-doughnut and axial beam have efficiencies of $87 \%, 85 \%, 89 \%, 78 \%$ and $82 \%$, respectively.

Within the net pattern bandwidth, it is observed that the antenna gain in the direction maximum radiation varies from $5.77 \mathrm{dBi}$ to $6.64 \mathrm{dBi}$ for single feeding tilted beam configuration and it varies from $6.16 \mathrm{dBi}$ to $5.97 \mathrm{dBi}$ for dual feeding tilted beam configuration, as shown in Fig. 12. The gain of the tilted-twin beams and semi-doughnut beams are found to be constant at $5.77 \mathrm{dBi}$ and $5.82 \mathrm{dBi}$. The gain of the axial beam shows a little variation from $8.3 \mathrm{dBi}$ to $8.1 \mathrm{dBi}$ within the net pattern bandwidth. 


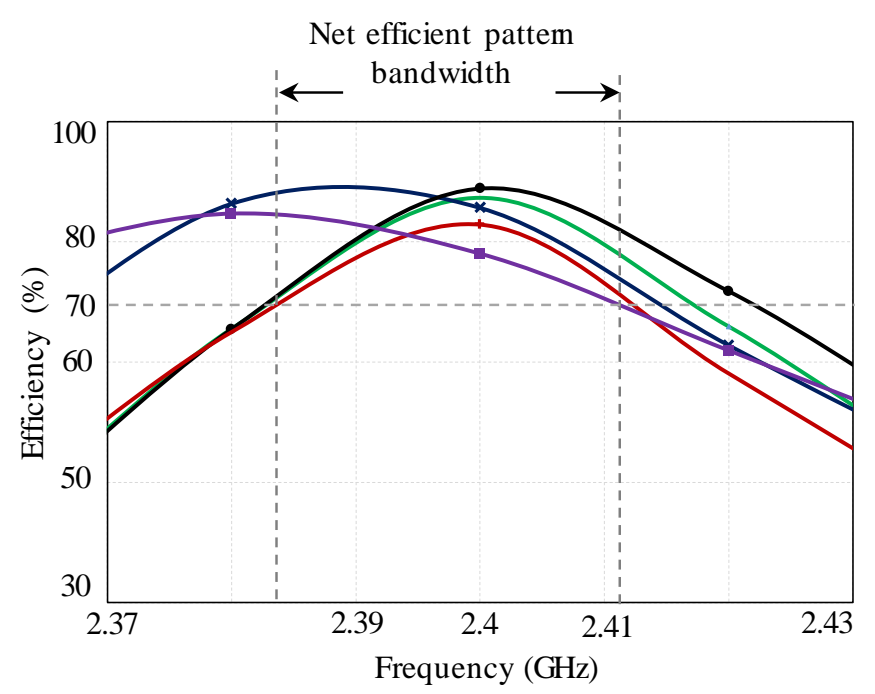

Single feeding tilted; $\longrightarrow$ Dual feeding tilted;

Tilted-twin; $=$ Semi doughnut; 1 Axial;

Fig. 11. Total efficiency of the antenna for different types of beams presented in sections III and IV.

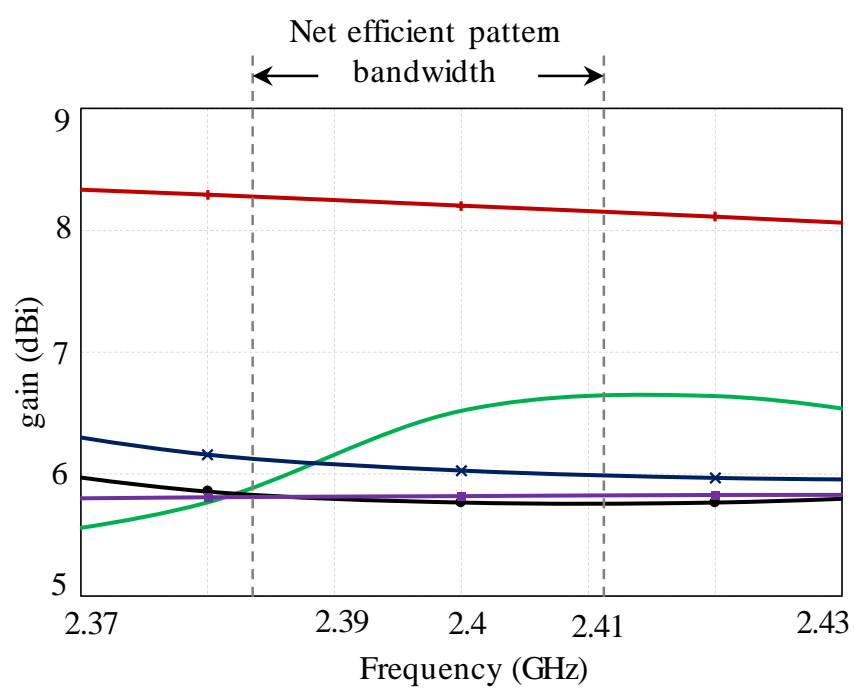

Single feeding tilted; $\longleftrightarrow$ Dual feeding tilted;

Tilted-twin; - Semi doughnut; 1 Axial;

Fig. 12. Gain of the antenna in the maximum direction of the radiation for different types of beams presented in sections III and IV.

\section{APPLICATION}

From application stand point the proposed antenna is designed for the next generation of vehicular applications. The proposed architecture aims to transform the internet access from High Throughput Satellites (HTS) and base stations, especially in weak electromagnetic environments. In these weak signal zones, conventional enhancement technologies like omni antenna based MIMO (Multiple Input Multiple
Output) struggle to provide significant gains. Being low profile the proposed antenna can easily be placed on the panoramic roofs of vehicles which are now are being made of variety of non-metallic surfaces. A depiction of how directive multiple beams can enable high SNR, and provide an ability to communicate with both satellite and terrestrial infrastructure is shown in Fig. 13.

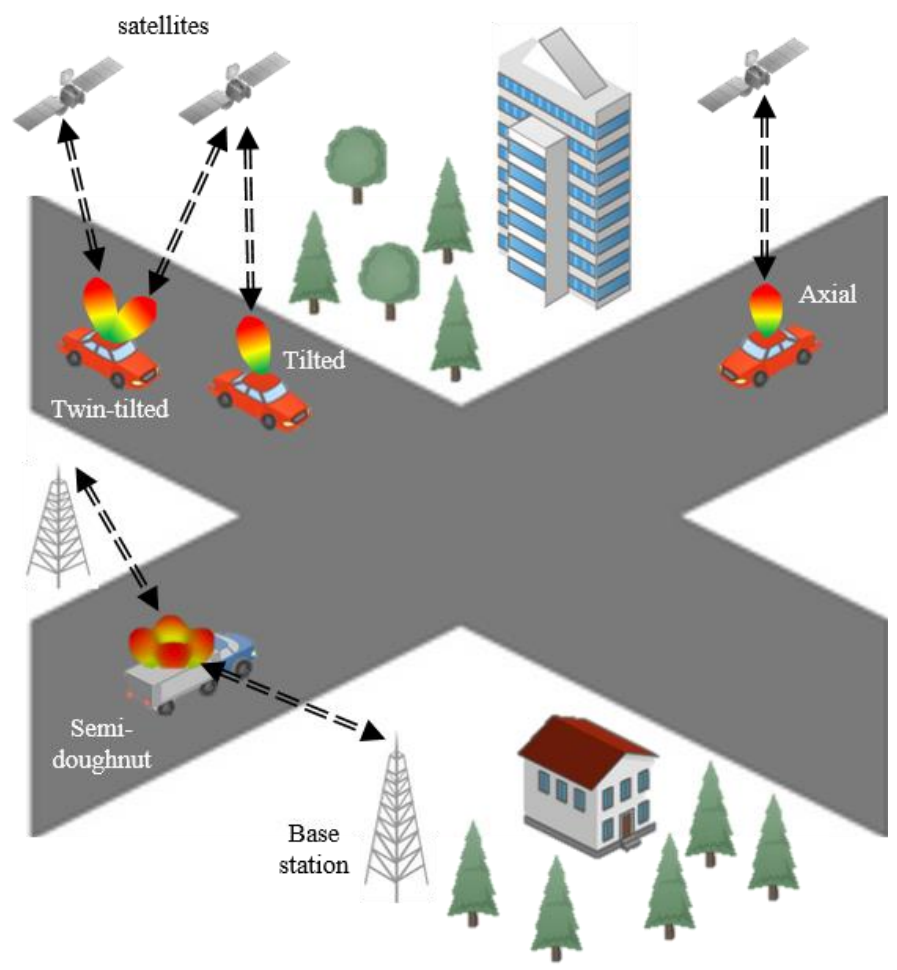

Fig. 13. Vehicular networking using multiple patterns to improve connectivity.

\section{CONCLUSION}

A twelve-beam low-profile $\left(\lambda_{0} / 83\right)$ printed patch antenna is presented for pattern reconfigurable applications. The antenna was designed to operate over a test frequency of $2.4 \mathrm{GHz}$ $(802.11 \mathrm{~b} / \mathrm{g} / \mathrm{n}) \mathrm{WiFi}$ band. The antenna exploits edge currents on the corners of the patch to produce eight tilted beams. The same antenna using dual feeding is also capable of generating two tilted-twin beams. Using four ports feeding it also generates a semi-doughnut radiation and an axial beam. Thus, with a total of twelve beams and a low profile structure the proposed antenna is an excellent candidate for future high throughput vehicular commutations. In addition, the ability of same antenna to communicate with both satellite and terrestrial infrastructure will enable vehicles to offer connected cars with IoT automotive cloud services

\section{REFERENCES}

[1] H. Mitsumoto, T. Murata, K. Takano, M. Fujita, S. Tanaka, S. Itoh, K. Shogen, N. Toyama and H. Miyazawa, "A mobile satellite news gathering system using a flat antenna," IEEE Trans. Broadcast., vol. 42, no. 3, pp.272-277, Sep. 1996.

[2] C. M. Nieh, C. Wei and J. Lin, "Concurrent detection of vibration and distance using unmodulated cw doppler vibration radar with an adaptive 
beam-steering antenna," IEEE Trans. Microwave Theory and Techniques, vol. 63, no. 6, pp. 2069-2078, Jun 2015.

[3] M.Z.M. Nor, S.K.A. Rahim, M.I. Sabran, P. J. Soh, and G.A.E. Vandenbosch, "Dual-band, switched-beam, reconfigurable antenna for WLAN applications," IEEE Antennas Wireless Propag. Lett., IEEE, vol.12, pp.1500-1503, 2013.

[4] D. M. Pozar, "Finite phased arrays of rectangular microstrip patches," IEEE Trans. Antennas Propag., vol.34, no.5, pp.658-665, May 1986.

[5] A.Mehta and D.Mirshekar-Syahkal, "Spiral antenna with adaptive radiation pattern under electronic control," Proc. IEEE Antennas Propag. Soc. Int. Symp., Monterey, CA, USA, Jun. 2004, vol. 1, pp. 843-846.

[6] A. Mehta, D. Mirshekar-Syahkal, and H. Nakano, "Beam adaptive single arm rectangular spiral antenna with switches," IEE Proc. Microwave, Antennas Propag., vol. 153, no. 1, pp. 13-18, 2006.

[7] G. H. Huff and J. T. Bernhard, "Integration of packaged RF MEMS switches with radiation pattern reconfigurable square spiral microstrip antennas," IEEE Trans. Antennas Propag., vol. 54, no. 2, pp. 464-469, Feb. 2006.

[8] C. W. Jung, M. Lee, G. P. Li, and F. De Flaviis, "Reconfigurable scanbeam single-arm spiral antenna integrated with RF-MEMS switches," IEEE Trans. Antennas Propag., vol. 54, pp. 455-463, Feb. 2006.

[9] A. Pal, A. Mehta, D. Mirshekar-Syahkal and P. J. Massey, "Doughnut and tilted beam generation using a single printed star antenna," IEEE Trans. Antennas Propag., vol. 57, no. 10, pp. 3413-3418, Oct. 2009.

[10] A. Mehta and D. Mirshekar-Syahkal, "Pattern steerable square loop antenna," IEEE Electron. Lett., pp. 491-493, Apr. 2007.

[11] A. Pal, A. Mehta, D. Mirshekar-Syahkal, and P. J. Massey, "Short circuited feed terminations on beam steering square loop antennas," IEEE Electron. Lett., vol. 44, no. 24, pp. 1389-1390, Nov. 2008.

[12] P. Deo, A. Mehta, D. Mirshekar-Syahkal, P. J. Massey and H. Nakano, "Thickness reduction and performance enhancement of steerable square loop antenna using hybrid high impedance surface," IEEE Trans. Antennas Propag., vol. 58, no. 5. pp. 1477-1485, May, 2010.

[13] A. Pal, A. Mehta, D. Mirshekar-Syahkal, P. Deo, H. Nakano, "Dual-band low-profile capacitively coupled beam-steerable square-loop antenna," IEEE Trans. Antennas Propag., vol.62, no.3, pp.1204-1211, Mar. 2014.

[14] M. S. Alam and A. M. Abbosh, "Beam-steerable planar antenna using circular disc and four pin-controlled tapered stubs for WiMAX and WLAN applications," IEEE Antennas Wireless Propag. Lett., vol. 15, pp. 980-983, 2016.

[15] Y. Y. Bai, S. Xiao, C. Liu, X. Shuai, and B. Z. Wang, "Design of pattern reconfigurable antennas based on a two-element dipole array model," IEEE Trans. Antennas Propag. Vol. 61, no. 9, pp. 4867-4871, 2013.

[16] S. J. Shi and W. P. Ding, "Radiation pattern reconfigurable microstrip antenna for WiMAX application," Electron. Lett. Vol. 51, no. 9, pp. 662-664, 2015.

[17] S. Nair and M. J. Ammann, "Reconfigurable antenna with elevation and azimuth beam switching," IEEE Antennas Wireless Propag. Lett., vol.9, pp.367-370, Apr. 2010.

[18] M. Jusoh, T. Aboufoul, T. Sabapathy, A. Alomainy and M. R. Kamarudin, "Pattern-reconfigurable microstrip patch antenna with multidirectional beam for wimax application," IEEE Antennas Wireless Propag. Lett., vol.13, pp.860-863, Apr. 2014.

[19] D. Heberling, and C. Oikonomopoulos-Zachos, "Multiport antennas for MIMO-systems" Proc. Loughbourough Antennas \& Propagation Conference, Loughborough, UK, pp. 65-70, Nov. 2009.

[20] W. Cao, B. Zhang, A. Liu, T. Yu, D. Guo, and K. Pan, "A reconfigurable microstrip antenna with radiation pattern selectivity and polarisation diversity", IEEE Antennas Wireless Propag. Lett., vol. 11, pp. 453 - 456, Apr. 2012

[21] A. Narbudowicz, X. L. Bao, M. J. Ammann, H. Shakhtour, and D. Heberling, "Circularly Polarized Antenna with Steerable Dipole-like Radiation Pattern," IEEE Trans. Antennas Propag., vol. 62, no. 2, pp. 519-526, Feb. 2014.

[22] H. Nakano, M. Iwatsuki, M. Sakurai, and J. Yamauchi, "Cavity backed rectangular aperture antenna with application to a titled fan beam array antenna," IEEE Trans. Antennas Propag., vol. 51, no. 4, pp. 712-717, Apr. 2003.

[23] G. Q. Luo, Z. F. Hu, L. Xi Dong and Ling-Ling Sun, "Planar slot antenna backed by substrate integrated waveguide cavity," IEEE Antennas Wireless Propag. Lett., vol.7, pp.236-239, Apr. 2008.
[24] F. Xu , K. Wu and X. Zhang "Periodic leaky-wave antenna for millimeter wave applications based on substrate integrated waveguide", IEEE Trans. Antennas Propag., vol. 58, no. 2, pp.340- 347, Feb. 2010.

[25] Q. H. Lai, W. Hong, Z. Q. Kuai, Y. S. hang and K. Wu "Half-mode substrate integrated waveguide transverse slot array antennas," IEEE Trans. Antennas Propag., vol. 57, no. 4, pp.1064-1072, Apr. 2009.

[26] C. Jin, R. Li, A. Alphones and X. Bao, "Quarter-mode substrate integrated waveguide and its application to antennas design," IEEE Trans. Antennas Propag., vol.61, no.6, pp.2921-2928, Jun. 2013.

[27] C. Jin, R. Li, S. Hu, S. Zhang, K. F. Chang and B. Zheng, "Self-Shielded Circularly Polarized Antenna-in-Package Based on Quarter Mode Substrate Integrated Waveguide Subarray," IEEE Trans. Components, Packaging and Manufacturing Technology, vol.4, no.3, pp. 392-399, Mar. 2014.

[28] D. Kim, J. W. Lee, C. S. Cho and T. K. Lee, "X-band circular ring-slot antenna embedded in single-layered SIW for circular polarization," Electron. Lett., vol. 45, no. 13, pp.668-669, Jun. 2009.

[29] A. Suntives and S. V. Hum, "A Fixed-Frequency Beam-Steerable Half-Mode Substrate Integrated Waveguide Leaky-Wave Antenna," IEEE Trans. Antennas Propag., vol. 60, no. 5, pp. 2540-2544, May 2012.

[30] W.S.T. Rowe and R. B. Waterhouse, "Edge-fed patch antennas with reduced spurious radiation," IEEE Trans. Antennas Propag., vol.53, no.5, pp.1785-1790, May 2005.

[31] CST GmbH. Darmstadt, Germany, [online] http://www.cst.com.

[32] http://01ff925.netsolhost.com/pdf/material/taconic-laminate_material_ guide.pdf

[33] P. Sorrells, "Twin Beam technology adds immediate capacity without additional antennas," White paper, May, 2013, [Online]. Available: http://file:///C:/Users/rflab/Downloads/Six-Sector_Twin_Beam_WP-106 683.pdf.

[34] A. Pal, A. Mehta, D. Mirshekar-Syahkal, and H. Nakano, "A square-loop antenna with 4-Port feeding network generating semi-doughnut pattern for vehicular and wireless applications," IEEE Antennas Wireless Propag. Lett., vol.10, pp. 338-341, Apr, 2011.

[35] M. E. Marhic, A. Mehta and A. Pal, "Theory and generation of circularly polarized waves by antenna arrays with N-fold rotational symmetry," IEEE Antennas Wireless Propag. Lett., vol. 10, pp. 1441-1444, Dec. 2011. 